\title{
Exploring E-Business in SMEs
}

\author{
K. M. Anwarul Islam ${ }^{1}$ \\ Md. Rezaul Karim Miajee ${ }^{1}$ \\ ${ }^{1}$ Department of Business Administration, The Millennium University, Dhaka, Bangladesh \\ Correspondence: Department of Business Administration, The Millennium University, Dhaka, Bangladesh
}

Received: November 21, $2017 \quad$ Accepted: November 23, $2017 \quad$ Online Published: January 9, 2018

\begin{abstract}
Surviving hypothesis proposes that organizations receive the best rewards from the Internet by coordinating business frameworks and by changing business forms. For sure, such incorporation is the ultimate result of development models that hypothesize organizations move in stages starting with one utilize then onto the next. In any case, there is little proof that little and medium-sized endeavors accomplish more than create sites and receive email. In this paper contextual investigations of 12 SMEs are utilized to investigate the selection of Internet technologies. The key issues restricting Internet reception are considered. A key model is then built up that recommends the criteria for selection are needy upon SME proprietors' demeanor to development. This prompts the improvement of an unexpected (or "transporter") display instead of a "phases" model of Internet appropriation. This examination has vital arrangement suggestions as, in any event in the UK and in Europe, government SME e-business reception assistance is predicated upon a selection "ladder".If no step or stages show is proper for SME then government consolation to move starting with one dimension then onto the next is confused. The transporter demonstrates distinguishes four jobs for Internet advances in SMEs - brochureware, support, opportunity and system. These are driven by business development arranging and saw Internet esteem.
\end{abstract}

Keywords: SMEs, E-Business, Business Model.

\section{Defining E-Business}

E-business has grown rapidly over the last few years. The Internet and the development of the World Wide Web have opened up the potential of the global information society. Growth is driven by accessibility of the Internet; firms using the Internet for electronic transaction; digital delivery of informational goods and services, such as, music and finally retail sale of tangible goods. E-business is seen as a broad generic term for the development of strategies for firms to use the Internet. There are three main aspects to e-business: intra-organizational (internal to the firm); inter-organizational (between firms in supply chain) and e-commerce (customer to firm). Both intraorganizational and inter-organizational e-business is usually developed to improve productivity through better internal communication and processes. E-commerce is seen as providing an alternative route to market for both tangible and intangible goods. 
Precise Internet benefits remain unclear, but speculation suggests that greatest benefits occur under full supply chain integration. Implementation is thought to progress through several stages and evolves as businesses recognize the benefits. Presents a summary of four stages models. These different stages models suggest that firm's progress e-business through stages as they identify the benefits. They all follow a similar path suggesting a web presence is found early on in the decision to adopt e-business. The only difference is in the Teo and Pian model, perhaps due to its recency, when the hype of having a web presence has died down, alternatively there may be demographic factors as the study was carried out in Singapore. It is also interesting to recognize the power of e-business for business scope redefinition. However, integrating these models leads to a summary model

\section{E-business and SMEs}

SMEs believe that the Internet will enable them to reach wider geographical markets and increase customers.However e-business adoption is often reactive and opportunistic rather than strategic. There is little evidence of business strategy driving Internet adoption among SMEs. However, strategic commitment is critical in Singaporean SMEs. Indeed, Internet adoption is faster when SMEs recognize a business need.

In common with most large businesses, SMEs have embraced the use of e-mail, with $90 \%$ of SMEs using it regularly a year after its introduction to the business. There is evidence that many have also developed "brochureware" web sites.

However, there is little indication that many SMEs have integrated their web sites with their back-office systems. While many see value in e-mail and web sites, there is scant evidence of decisions to invest in internal networks or e-business systems.

Currently, the e-business growth path for SMEs appears to stop at Stage 2 (interaction) with only a few progressing to Stage 3 (transaction). Stage 4 is only recognized once SMEs identify business benefits.

\section{Influencing Factors}

One Internet appropriation display recommends there are three principle factors that impact SMEs' choices - saw benefits, hierarchical status and outer weights. There are three perspectives to saw advantage. In the first place, productivity benefits emerge from enhanced correspondence utilizing email; this is likewise distinguished.

Second, adequacy benefits acquire from the capacity to accumulate research and contender data, additionally recognized by Poon. Third, utilization of the Internet shows a cutting edge picture and enhances SME advancement.

Hierarchical status for Internet selection is represented in the SME proprietor. SMEs don't see Internet selection as a data innovation issue, however as a business one. SMEs that are pulled in to

Web based trade will in general be more enterprising, daring individuals, inventive and perpetually, innovative . A second authoritative availability factor is the prerequisite for SMEs to have satisfactory data framework set up to get to the Internet .

The last factor, outside weight, is fundamentally from clients, however providers and representatives are additionally impacting components. While Poon perceives that client weight is compelling, there is proof that an absence of client utilize is an inhibitor, especially of email .

An investigation of e-business adopters and non-adopters in Chile found that hierarchical status is the most essential factor in the choice to embrace. Authoritative availability suggests sufficient innovative and money related assets to empower e-business selection. The adequacy saw advantage of administrative efficiency was observed to be next essential, with outer weight third . 
Consequently, ebb and flow inquire about recommends that various components impact Internet selection and improvement in SMEs. Business require and saw benefits figure conspicuously in SME Internet advancement. In any case, regardless of their notoriety in early IS reception investigate and their instinctive intrigue, there is little proof that SMEs pursue a "phases of development" show for Internet appropriation. An unexpected model that includes "transportation" starting with one utilize then onto the next without the understood thought of development might be more valuable for comprehension SME Internet selection.

One clarification for this absence of proof is the penchant of past research to consider SMEs as homogenous gathering. Be that as it may, in building up the center predominance show, SME look into necessities to perceive heterogeneity. It is realized that proprietor state of mind and business technique impact IS selection, and may do likewise for Internet appropriation. Henceforth, this section tries to decide if SME Internet reception systems are dependent upon variables, for example, proprietors' state of mind, business procedure, saw advantages and client impact.

\section{References}

Rangone, A. (1999). A resource-based approach to strategy analysis in smallmedium sized enterprises. Small Business Economics, 12: 233-248.

Reid, G. (1999). Information Systems Development in the Small Firm, CRIEFF Discussion Paper Series No. 0002. ISSN 1364-453-X, University of St Andrews, Scotland.

Reid, G. and Jacobsen, C. (1988). The Small Entrepreneurial Firm. Aberdeen University Press, UK.

Sanchez, R., Heene, A. and Thomas, H. (1996). Towards the theory and practice of competence-based competition. In Sanchez, et al. (Eds). Dynamics of Competence-Based Competition. Elsevier Science Ltd, Kidlington, Oxford.

Santarelli, E. and D'Altri, S. (2003). The diffusion of e-commerce among SMEs: theoretical implications and empirical evidence. Small Business Economics, 21: 272-283.

\section{Copyrights}

Copyright for this article is retained by the author(s), with first publication rights granted to the journal.

This is an open-access article distributed under the terms and conditions of the Creative Commons Attribution license (http://creativecommons.org/licenses/by/4.0/). 